\title{
Primeiros passos de maturidade a caminho da reintegração cromática diferenciada em pintura de cavalete em Portugal
}

\author{
Ana Bailão, Frederico Henriques, Madalena Cabral, Alexandre Gonçalves
}

Resumo: O objectivo deste artigo é analisar e contextualizar o processo de maturidade da reintegração cromática diferenciada em pintura de cavalete ao longo do século XX, em Portugal. Para tal, é feito um levantamento dos critérios com base nas acções de reintegração cromática efectuadas por Abel de Moura e Fernando Mardel em dois painéis de pintura sobre madeira: no tríptico da "Pietá com dois Santos", pertencente ao Museu de Artes Decorativas Portuguesas, Fundação Ricardo do Espírito Santo Silva (FRESS), e no tríptico da Igreja da Encarnação, actualmente no Museu de Arte Sacra do Funchal. Através do uso de sistemas de informação geográfica é determinada a área de reintegração.

Palavras-chave: reintegração cromática diferenciada, Abel de Moura, Fernando Mardel, SIG.

Resumen: El objetivo de este trabajo es analizar y contextualizar la reintegración cromática diferenciada en la pintura de caballete durante el siglo XX en Portugal. Se trata de un estudio de los criterios con base en las actividades de reintegración cromática llevadas a cabo por Abel de Moura y Fernando Mardel en dos paneles de pinturas sobre madera: el tríptico de "Pietá com dois Santos", perteneciente a lo Museu de Artes Decorativas Portuguesas, Fundação Ricardo do Espírito Santo Silva (FRESS) y el tríptico de la Iglesia de "Encarnação", en la actualidad en el Museo de Arte Sacro en Funchal. El área reintegrada es valorada mediante el uso de sistemas de información geográfica.

Palabras clave: reintegración cromática diferenciable, Abel de Moura, Fernando Mardel, SIG.

Abstract: The aim of this paper is to analyze and contextualise differential chromatic reintegration in easel painting during the $20^{\text {th }}$ century in Portugal. It is a survey of the criteria based on chromatic reintegration activities carried out by Abel de Moura and Fernando Mardel on two wood panel paintings: the triptych "Piéta com dois Santos", belonging to the Portuguese Decorative Arts Museum, Fundação Ricardo do Espírito Santo Silva (FRESS) and the triptych of the Church of "Encarnação", currently at the Sacred Art Museum in Funchal. Through geographic information systems the reintegration area is determined.

Keywords: distinctive retouching, Abel de Moura, Fernando Mardel, GIS.

\section{Introdução}

A reintegração cromática tem como objectivo minorar as evidências da deterioração da obra e restabelecer a interpretação visual das formas e dos conteúdos iconográficos dos objectos artísticos. Este processo pode implicar uma acção nas lacunas pictóricas e nos desgastes da camada cromática.

Inicialmente efectuada por pintores-restauradores, a reintegração tinha por propósito somente a valorização estética da obra. Foram muitas as pinturas repintadas total ou parcialmente para dissimular os danos ocasionados por limpezas nefastas, por questões de gosto pessoal do proprietário ou por conjunturas políticas e eclesiásticas. Face a isso, pensamos que foi a partir do final o século XIX que se começou a alicerçar um processo de maturidade em Portugal. 
A descoberta dos Painéis de São Vicente, de Nuno Gonçalves, deu início a um projecto de intervenção pouco comum na recuperação do património português, no qual se equacionou a melhor forma de actuar nas lacunas (Gonçalves, 1960: 26, 35). Luciano Freire, no restauro de 1911, além de ter denominado a tarefa por "reintegração", parece ter colocado em prática novos ideais, através da utilização de um sub-tom nas lacunas dos painéis (Vieira, 1923: 28).

O intuito deste texto é o de apresentar dois casos de reintegração diferenciada, realizados no final da década de 1940 na Oficina de Restauro do Instituto para Exame e Restauro de Obras de Arte, oficializado em 1965 como Instituto José de Figueiredo (IJF) (Couto, 1952: 11, 12). Pretendemos dar a conhecer algumas condicionantes da época e os modelos de reintegração propostos por Abel de Moura e Fernando Mardel. Parte da informação indicada no ponto dois deste artigo, referente à reintegração cromática, foi recentemente estudada no que respeita à metodologia e às técnicas dessa reintegração em pintura de cavalete (Bailão, 2010).

Os casos de estudo utilizados para a contextualização são: uma obra quinhentista da Oficina de Lisboa, tríptico da "Pietá com dois Santos" [Figura 1], do Museu da Fundação Ricardo do Espírito Santo Silva (FRESS) e o tríptico da "Encarnação" [Figura 2], actualmente no Museu de Arte Sacra do Funchal, na Madeira.
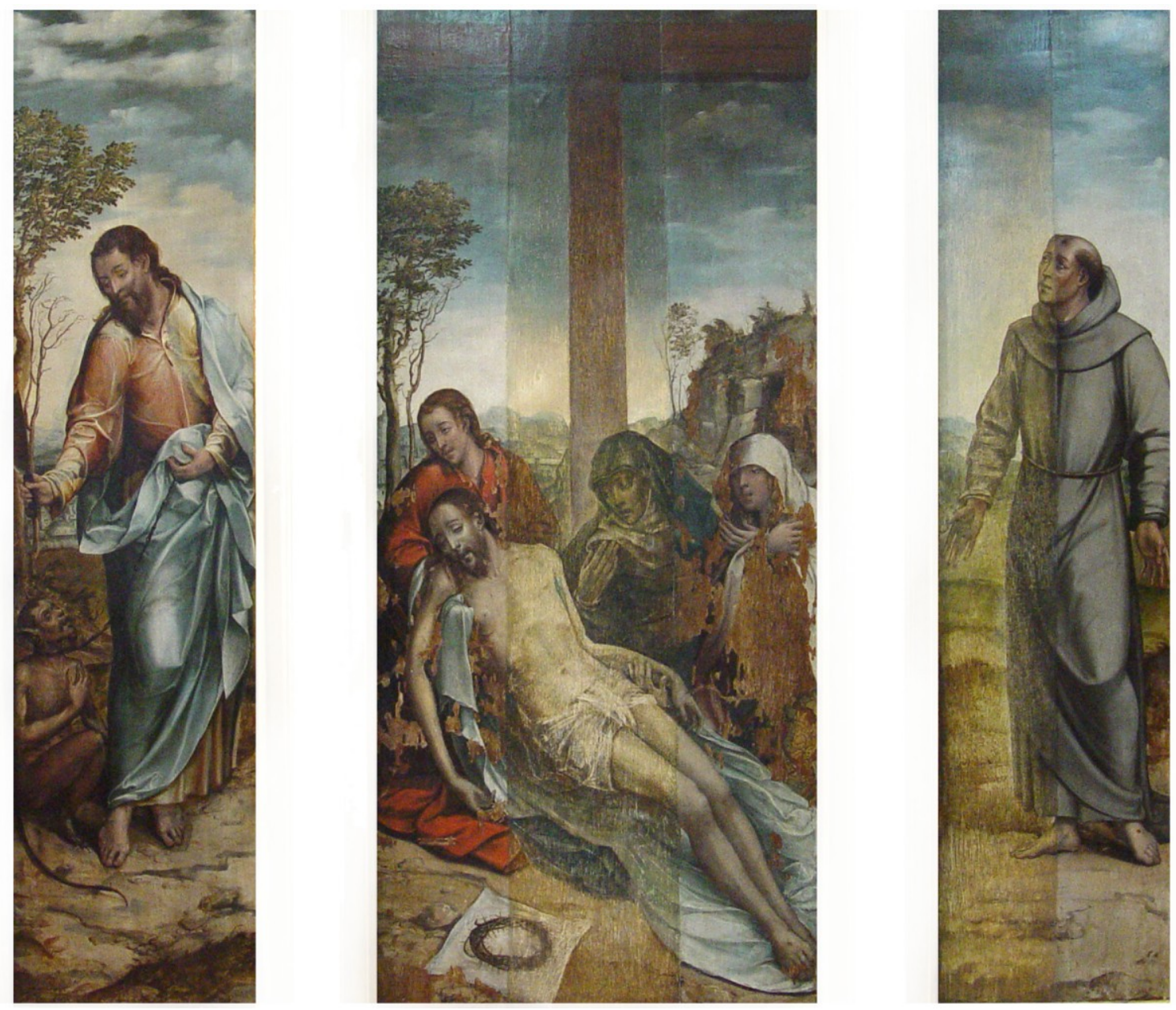

Figura 1. Tríptico "Pietá com dois Santos". Reintegração cromática diferenciada de Abel de Moura no painel lateral de São Francisco e no painel Central (Fotografias de Frederico Henriques). Direitos reservados ao Museu de Artes Decorativas Portuguesas, Fundação Ricardo do Espírito Santo Silva. N. o de inventário 33, 34 e 35 


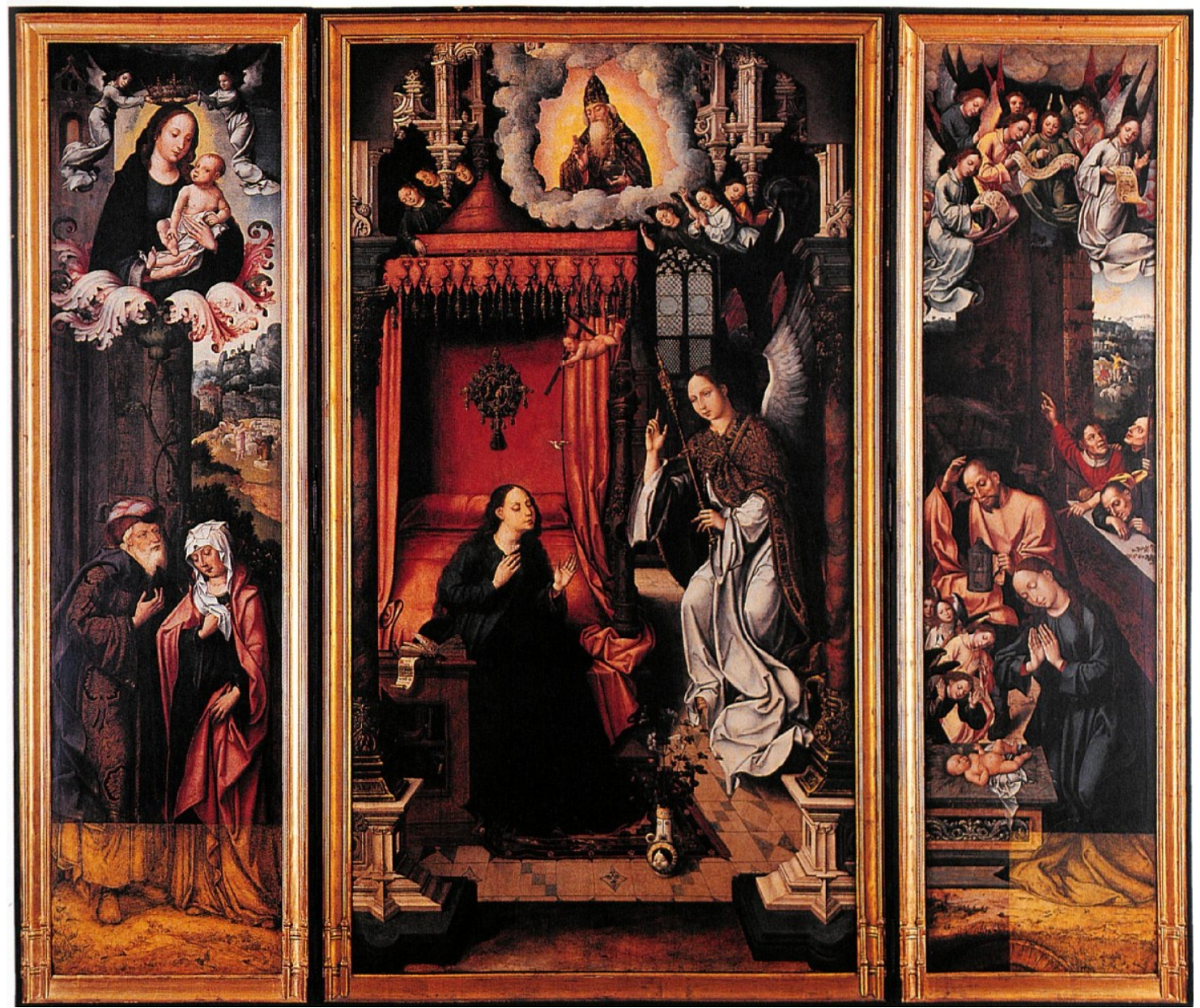

Figura 2. Tríptico da Encarnação. Reintegração diferenciada de Fernando Mardel nos painéis esquerdo e direito (Extraído de CLODE, L.; PEREIRA, F. A. B. (1997). Museu de arte Sacra do Funchal. A Arte Fflamenga. Lisboa: Edicarte, p. 71).

\section{A reintegração cromática}

\subsection{O conceito}

O uso da palavra "reintegração" em Portugal, como hoje a entendemos, encontra-se no ano de 1911, pela mão de Luciano Freire [1], no âmbito da redacção de um relatório de conservação e restauro, intitulado "Elementos para um relatório acerca do tratamento da pintura antiga em Portugal segundo notas tomadas no período da execução desses trabalhos". Trata-se de um texto de carácter pessoal, no qual o autor anota as suas memórias e intervenções. Este termo, "reintegração" [2] foi proposto e aceite em público por Afonso Lopes Vieira (Vieira, 1923: 10), no ano de 1922, durante uma conferência realizada no Museu Nacional de Arte Antiga de Lisboa (MNAA), em substituição do vocábulo "restauro", por atribuir uma conotação negativa a este último. O conceito foi novamente abordado em 1945, numa comunicação de Luís de Ortigão Burnay sobre o tema (Burnay, 1945: 61-70).

Segundo Pilar Legorburu Escudero, a palavra "reintegração" começou a ser usada no Istituto Centrale per il Restauro (ICR), em Roma, a partir do ano de 1945 (Legorburu Escudero, 1995: 254), cerca de 
trinta e quatro anos após o relatório de Luciano Freire. Todavia, trata-se de uma terminologia que varia consoante o país ${ }^{[3]}$, não se podendo generalizar.

Esta intervenção pode denominar-se, consoante as fontes, por reintegração ou integração, cromática ou pictórica. $\mathrm{Na}$ gíria, e com mais frequência, utiliza-se o termo "retoque" que significa a «última correcção ou aperfeiçoamento de detalhes numa obra artística» (Teixeira, 1985: 198). Esta designação adequava-se aos critérios e intervenções realizadas até ao final do século XX por pintores-restauradores. Todavia, a partir de 1989, com o aparecimento das primeiras escolas superiores de conservação e restauro, em Lisboa e Tomar [4], impõem-se decisivamente novos critérios. A moderna figura do técnico de conservação e restauro, sem pretensões artísticas, distinta do pintor-restaurador e do restaurador, procura circunscrever a acção da reintegração cromática apenas à lacuna. Se bem que ainda não seja perfeitamente claro e assumido por todos os pares, consideramos o termo "retoque" desadequado à prática dos conservadores-restauradores portugueses do século XXI [5].

Os casos de estudo que iremos apresentar, apesar de terem sido executados por pintoresrestauradores ou restauradores, demonstram uma atitude crítica e respeitadora dos limites da lacuna, motivo pelo qual utilizamos o termo reintegração ao longo deste artigo. A palavra "diferenciada" escolheu-se pelo facto de sugerir uma distinção bastante evidente da técnica pictórica original.

\subsection{Mudanças de atitude teórica e técnica na reintegração}

As poucas informações que temos sobre as práticas oficinais de restauro em Portugal aparecem só a partir da segunda metade do século XVIII, dado que as receitas eram mantidas em estrito sigilo, numa aprendizagem feita de mestre para discípulo.

Em 1945, Luís de Ortigão Burnay, anota que “(...) no século XVII e sobretudo no século XVIII, se fizeram verdadeiros vandalismos devido à falta de aperfeiçoamentos científicos, e mais ainda, resultante duma menor experiência de hospital, como se poderia dizer medicamente falando" (Burnay, 1945: 62). Também Afonso Lopes Vieira fez referência às intervenções praticadas antes e durante o século XVIII. Segundo Vieira, as pinturas portuguesas "Primitivas" chegaram-nos todas repintadas " (...) a começar pelas táboas de Nuno Gonçalves, de cuja superfície foram desbastadas diversas crostas de repintura ignara” (Vieira, 1923: 12).

Através destas citações é possível perceber que as primeiras intervenções surgiam da necessidade de reparar as "qualidades estéticas" das obras em degradação. Realizadas por pintores, num regime mestre-aprendiz, com receituários personalizados para cada tratamento, limitavam-se a melhorar o aspecto das pinturas, consoante o gosto do proprietário, o estilo preponderante na época ou o seu próprio gosto [6].

Em 1885, Manuel de Macedo (1839-1921) publica um livro dedicado exclusivamente ao restauro de quadros. O autor estabeleceu pela primeira vez a diferença entre o artista e o restaurador. Para Macedo, o restaurador de pintura tem duas actividades distintas, a "restauração" e o "retoque". Por "restauração" entendeu ser somente um ofício, atento à degradação das obras e destinado a investigar os processos materiais e metodológicos aplicados em conservação e restauro; por "retoque", considerou ser a "parte artística" da actividade do restaurador (Macedo, 1885: 6). Apesar de ter alertado para o facto da acção de "retoque" ter de ser utilizada com cuidado e apenas quando indispensável, recomendou também a sua execução de modo mimético, seguindo a técnica pictórica. Na ausência de referências, sugeriu haver legitimidade por parte do restaurador, para reconstruir elementos, desde que feito “ (...) com modéstia, para evitar improvisar arbitrariamente qualquer pormenor" (Macedo, 1885: 39). Apesar de se detectar uma evolução no sentido da compreensão da obra, permanecem ambiguidades, sendo possível estabelecer uma linha de 
continuidade com as práticas anteriores a Macedo, quer ao nível dos produtos quer das metodologias de intervenção.

Após a instauração da República, em 1910, iniciou-se uma nova postura perante o Património. Alguns dos factores mais relevantes para esta mudança foram, do ponto de vista do restauro: as novas metodologias do pintor-restaurador Luciano Freire, por terem estabelecido uma linha de fronteira entre as práticas oficinais e as suas de carácter mais científico (Couto, 1955: 16; Vieira, 1923: 22); a responsabilidade conjunta assumida pelos conservadores dos Museus e pelos restauradores durante os restauros; a tomada de consciência sobre a necessidade de diagnosticar meticulosamente qualquer obra antes das acções de restauro, com recurso a métodos de exame e análise [7]; o surgimento em Portugal das primeiras teorias de restauro, divulgadas, sobretudo, através das publicações da Academia de Belas Artes e dos Museus.

O reconhecimento da reintegração começou a ser uma necessidade em Portugal no início do século XX. Veja-se a opinião de Luiz Reis Santos numa crítica a um trabalho de Freire sobre as intervenções realizadas antes de 1940: segundo Reis Santos "nos nossos restauros segue-se um critério com o qual não posso concordar: quando falta qualquer coisa num quadro antigo inventase!". O autor elucida o seu comentário com dois exemplos: o primeiro relativo a um painel do "Baptismo de Cristo" da Igreja de S. João Baptista de Tomar, no qual "fez-se de novo" duas pranchas em falta, sem "prevenir disto o público" (Santos, 1939: 47). Salienta ainda um painel do MNAA, procedente da igreja de S. Francisco de Évora, que segundo o autor se encontrava sem uma tábua e sobre a qual "resolveram (...) completar a composição e fazer de novo o desenho e a pintura da referida tábua" sem prevenir "o observador de que uma parte da figura que está de costas, no primeiro plano, foi inventada aos nossos dias! Eu chamo a isto um abuso contra os direitos artísticos do autor" (Santos, 1939: 48). As constatações de Luiz Reis Santos são uma prova e um testemunho do início de uma consciencialização da necessidade de diferenciação na reintegração.

Apesar de famosos por muitas controvérsias associadas às figuras representadas, os Painéis de São Vicente encontrados, segundo as fontes, num estado avançado de degradação, deram início a um projecto de intervenção pouco comum na recuperação do património português. Por acção de José de Figueiredo, os painéis foram para a oficina de restauro do Convento de São Francisco, onde Luciano Freire iniciou, em 1909, o tratamento de "beneficiação" das pinturas. Devidamente fotografadas para documentação e fundamentação da iniciativa, foram avaliadas e fiscalizadas durante todo o processo de restauro. Existem várias observações, compiladas no livro de Manuel Gonçalves acerca do restauro dos painéis ${ }^{[8]}$, sobre os "grosseiros" repintes a que as pinturas tinham sido submetidas antes de Freire. Pensamos ser este o momento de fronteira entre as práticas de repintura e o respeito pela lacuna e obra original. António Arroio [9], por exemplo, considerava que o "retoque devia ser, tanto quanto possível evitado, pois, em quadros que tivessem sofrido grande avaria, o retoque dominaria a pintura primitiva, e dar-lhe-hia falsa e anachronica apparencia" (Gonçalves, 1960: 35). Outros pensadores como Ramalho de Ortigão ${ }^{[10]}$ entendiam que "de forma alguma se deve procurar iludir o sítio retocado, sobretudo se se tratar de grandes faltas de tinta em pontos importantes; tanto mais que essa ilusão é sempre passageira" (Gonçalves, 1960: 26). O resultado final da intervenção de Luciano Freire parece ter seguido estas ideias [11], assim como o trabalho feito por Abel de Mora no tríptico da "Pietá com dois Santos" e Fernando Mardel no tríptico da "Encarnação".

Luís de Ortigão Burnay, seguidor atento da carreira de Helmut Ruhemann [12], disse em 1945 que o “(...) trabalho de reintegração consistirá rigorosamente em só tocar no estritamente necessário; o retoque só deve exercer-se nos pontos em que falte a tinta ou onde o preparo de base tenha caído. $\mathrm{O}$ retoque tem por fim unicamente harmonizar e valorizar o que de outra forma seria uma cacofonia (...)". Na primeira metade do século XX o objectivo não era ocultar os estragos das obras mas sim estudar os autores, as diferentes escolas, as técnicas, respeitando o original, a obra do 
criador (Burnay, 1945: 65, 67). Esta tomada de consciência pelo valor da obra de arte desencadeou teorias, umas a favor e outras contra o acto de reintegrar.

É provável que a reintegração cromática diferenciada tenha começado a ser executada mais frequentemente em Portugal a partir da década de 50 do século XX, na sequência do congresso do ICOM de 1949, em Roma, em que o Director do Museu Nacional de Arte Antiga, João Couto, Fernando Mardel e Abel de Moura, observaram junto de Cesare Brandi a reintegração realizada pelo ICR nos frescos de Lorenzo da Viterbo, na Cappella Mazzatosta da igreja de Santa Maria della Veritá [13], em Viterbo. É nesta altura, aproximadamente, que pensamos terem sido feitas as primeiras reintegrações cromáticas assumidamente diferenciadas em Portugal. Até ao momento verificámos apenas os dois casos que documentamos no nosso texto.

O tríptico da "Pietá com dois Santos" está anotado por João Couto como "muito degradado", com "ablação de grandes parcelas da pintura original" Segundo o mesmo autor, optou-se por completar o conjunto de forma a "restabelecer-se uma ligação racional com o existente" [Figura 3]. (Couto, 1952: 21).
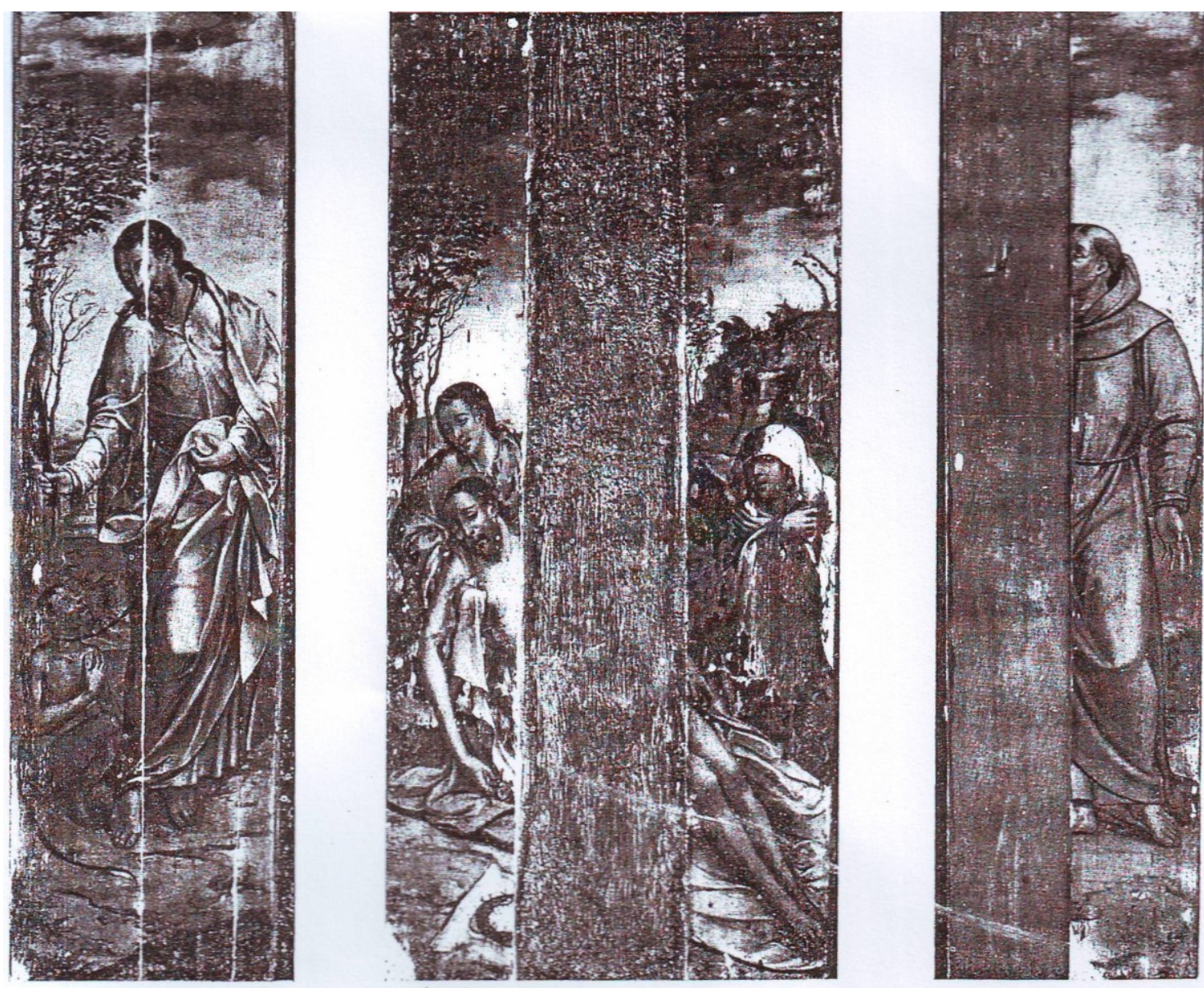

Figura 3. Tríptico "Pietá com dois Santos" antes do restauro de Abel Moura. (Extraído de MOURA, A. de. (1949). Les problèmes de la restauration et conservation de la Peinture. En XVI Congrés International D'Histoire de L'Art. Lisboa; Porto: Tipografia Minerva, p. 79).

A reintegração cromática foi efectuada pelo restaurador Abel de Moura, com uma técnica de traços incisivos [Figura 4], possivelmente inspirada no tratteggio. Sobre a reconstituição cromática e formal das figuras, perfeitamente pintadas, Abel de Moura fez traços "esgrafitados" ${ }^{[14]}$ sobre a camada 
cromática por ele pintada (Bailão, 2010: 26). Segundo Moura "a estética do fragmento não resiste à mutilação". Por isso optou por fazer um desenho análogo, em estilo, ao da pintura original, com tonalidades mais claras que as cores originais da pintura. Abel de Moura refere ainda que o uso de um tom neutro geral, não era opção uma vez que "perturba profundamente a harmonia geral da obra" (Moura, 1949: 82).

Como podemos constatar, há de facto uma consciência assumida, por parte de Moura, sobre a importância da pintura original, assim como uma maturidade para perceber a necessidade técnica em diferenciar a intervenção da obra em si. Este facto pode ser reforçado pelas palavras de Couto, em 1952, acerca da intervenção: "é certo que o restaurador podia ter imitado o trabalho do autor do painel (...) se o fizesse seria um erro condenável sob todos os pontos de vista" (Couto, 1952: 21).

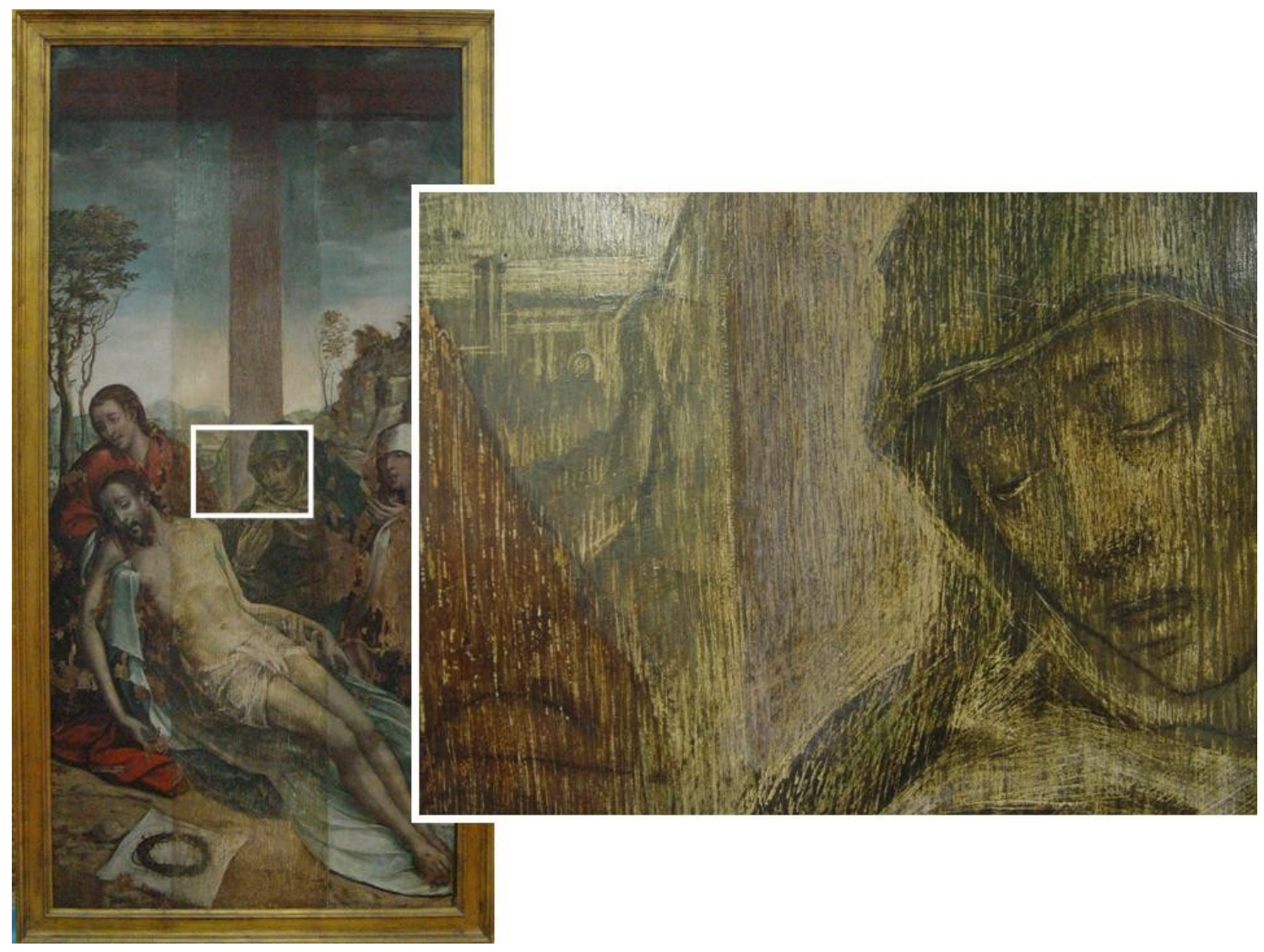

Figura 4. Tríptico "Pietá com dois Santos". Pormenor da reintegração de Abel de Moura no painel central (Fotografias de Frederico Henriques). Direitos reservados ao Museu de Artes Decorativas Portuguesas, Fundação Ricardo do Espírito Santo Silva. N. ${ }^{\circ}$ de inventário 35.

Mediante a observação da obra comprovamos que, de facto, os limites da lacuna foram escrupulosamente respeitados. Abel de Moura apenas reconstruiu as partes em falta no painel central e no painel lateral direito, não actuando sobre qualquer outra lacuna no tríptico. Podemos dizer, inclusive, que a opção tomada por Abel de Moura se enquadra na definição de "reintegração fragmentária", isto é, deixou certas lacunas visíveis enquanto outras, as maiores, foram reintegradas. Este método anotado por Emile-Mâle, é conveniente para pinturas muito degradadas ou para certas obras com valor documental, onde a reintegração deve apenas devolver a imagem coerente sem recorrer à recriação (Emile-Mâle, 1976: 100). 
A reintegração do segundo tríptico foi executada por Fernando Mardel. Segundo João Couto, o volante direito do painel tinha uma ablação de suporte na parte inferior, enquanto no volante esquerdo, o dano, também na parte inferior, não era tão profundo (Couto, 1952: 21). Esta mutilação parece ter sido feita por ocasião da transferência do painel da igreja de origem, Igreja de Nossa Senhora da Encarnação, para um dos altares da Igreja Nova de São Martinho (Zagallo, 1955: 11).

A solução encontrada para a intervenção, efectuada na Oficina de Restauro do MNAA, passou pela reconstituição " (...) talvez discutível (...)" das áreas desaparecidas "mas facilmente removível, que não ofendesse o aspecto inicial do retábulo" (Couto, 1952: 21). Com base no relatório de intervenção, manuscrito pelo próprio Fernando Mardel, houve a preocupação de não se "fazer uma pintura totalmente nova nesta extensa porção acrescentada mas prolongou-se o contorno do desenho num tom sépia de cor neutra [Figura 5] para apenas obter um conjunto mais agradável ao quadro" [15]. Esta reconstituição foi aprovada pelos peritos da Quinta Conferência Internacional do Restauro, reunida em Lisboa no ano de 1952 (Couto, 1955: 23).

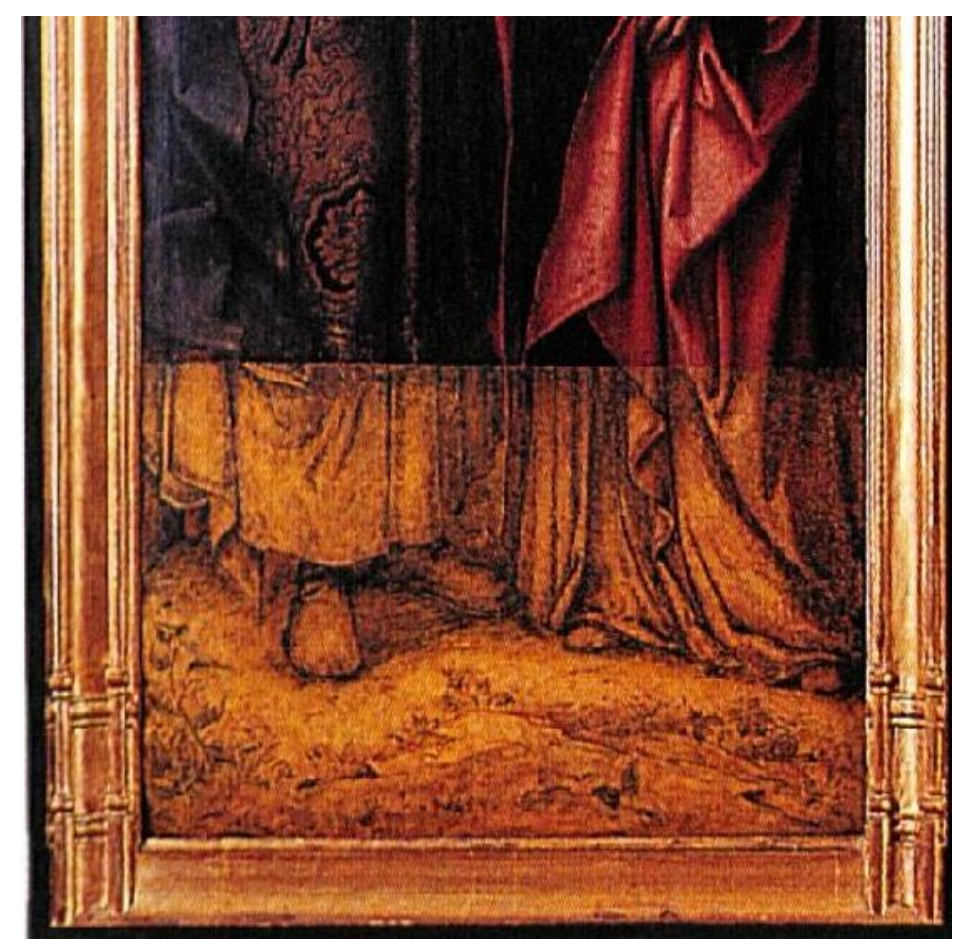

Figura 5. Pormenor da intervenção de Fernando Mardel no tríptico da Encarnação. (Extraído de CLODE, L.; PEREIRA, F. A. B. (1997). Museu de arte Sacra do Funchal. A Arte Fflamenga. Lisboa: Edicarte, p. 71).

\section{Espaço pictórico e área de intervenção}

As lacunas ao nível da percepção visual sobrepõem-se frequentemente à obra, ganhando protagonismo. A superfície pictórica adquire nova configuração perante os olhos do observador através da visualização da imprimitura, do preparo e do suporte. Estas interferências na continuidade coerente da imagem dependem também de factores como a forma da lacuna, a sua localização, a cor que a rodeia e a dimensão (Philippot, 1959: 5-18; Mora, Mora e Philippot, 1984: 309-310), entre outros. 
O objectivo, neste exercício, é avaliar a dimensão da área de intervenção do restaurador Abel de Moura no painel central da "Pietá" e no volante de "São Francisco", do tríptico da FRESS, através de ferramentas computacionais utilizadas no processamento de informação geográfica, sem necessidade de contacto físico com a superfície da obra ${ }^{[16]}$.

O modelo aplicado para a determinação do espaço pictórico e da área de intervenção foi efectuado através de uma técnica fotogramétrica, a fim de produzir uma ortofotografia, e com recurso a um Sistema de Informação Geográfica (SIG) se poder documentar a área de intervenção em cada obra.

A utilização destes recursos, assim como de outros métodos de exame e análise mais correntes e não invasivos (espectroscopia RAMAN, fluorescência de raios $\mathrm{X}$, etc.), de não contacto, é fundamental na documentação e caracterização de superfícies. Aliás, após colocar em primeiro plano a observação da obra, é no cruzamento de diversos métodos de abordagem ao objecto artístico, quer das ciências de caracterização histórica e artística, quer das ciências de componente analítica e laboratorial, que se encontram e alicerçam as práticas da disciplina de Conservação e Restauro.

\subsection{Fotogrametria e ortofotografia}

A fotogrametria é a ciência e arte de determinar a dimensão métrica e formal dos objectos, por análise de imagens capturadas em película ou por meios electrónicos (MacDonald, 2006: 173). A ortofotografia é uma imagem semelhante à que resultaria de uma perspectiva paralela ao terreno, segundo uma direcção vertical (Casaca, Matos e Baio, 2000: 259, 280), como se tratasse de uma vista ortogonal, planimetricamente correcta, que tem a possibilidade de ser usada como mapa para medir distâncias, ângulos, posições e áreas, o que, naturalmente, não pode ser feito com imagens em perspectiva (Henriques, Gonçalves, Bailão e Calvo, 2009: 13-15). Se bem que se possam utilizar registos fotográficos digitais tradicionais para documentar uma obra de arte, onde com alguma perícia se podem minimizar nas imagens os efeitos da distorção, ocasionada pela perspectiva central ou cónica, a ortofotografia obtida através de um processo fotogramétrico de curto alcance constitui um documento de registo de uma superfície pictórica passível de ser utilizado num SIG. Um documento que, na forma de imagem digital ou matricial (raster), é susceptível de se utilizar, por exemplo, no mapeamento de patologias do tipo de lacunas (Henriques, Gonçalves, Bailão e Calvo, 2009: 13-15). Ou então, produzindo a partir dessa imagem matricial um documento vectorial, na forma de mapa temático, para anotar fenómenos de degradação com cores indicativas das tipologias de danos (Arjonilla Álvarez, 2008: 87-95).

No processo de quantificação da área de intervenção fez-se numa primeira fase com um programa fotogramétrico (Photomodeler $($ ) um levantamento fotogramétrico com imagens múltiplas, com o objectivo de obter a ortofotografia [Figura 6]. O método recorre ao modelo de Peter Waldhäusl (1994: 426-429). Calibrou-se a câmara fotográfica, fez-se a importação de imagens para um software que opera em modelação por triangulação, definiram-se pontos homólogos, produziu-se um modelo tridimensional e extraiu-se a ortofotografia.

\subsection{Determinação da área de intervenção}

Efectuar fotografias, documentar e gerir a informação são tarefas essenciais na Conservação do Património (Eppich, R.; Chabbi, A., 2007 e Letellier, R., 2007). Foi nessa óptica que se abordou o estudo em torno da extracção de características geométricas em SIG.

A interpretação do espaço das grandes áreas de lacunas reintegradas, especificamente a tábua esquerda do painel de "São Francisco" e a central no painel da Pietá, decorreu em ambiente ArcMap ${ }^{\circledR}$, operando-se as seguintes fases: importação da imagem-ortofotografia, referenciação de pontos nos cantos da imagem (georeference) e reamostragem, produção da imagem rectificada com 
células de dimensão que traduzisse um nível de detalhe adequado (resolução espacial de $1 \mathrm{~mm}^{2}$ ), criação de polígonos por digitalização dos limites das áreas de reintegração, conversão dos polígonos referidos em formato matricial e determinação das áreas por quantificação percentual de células.

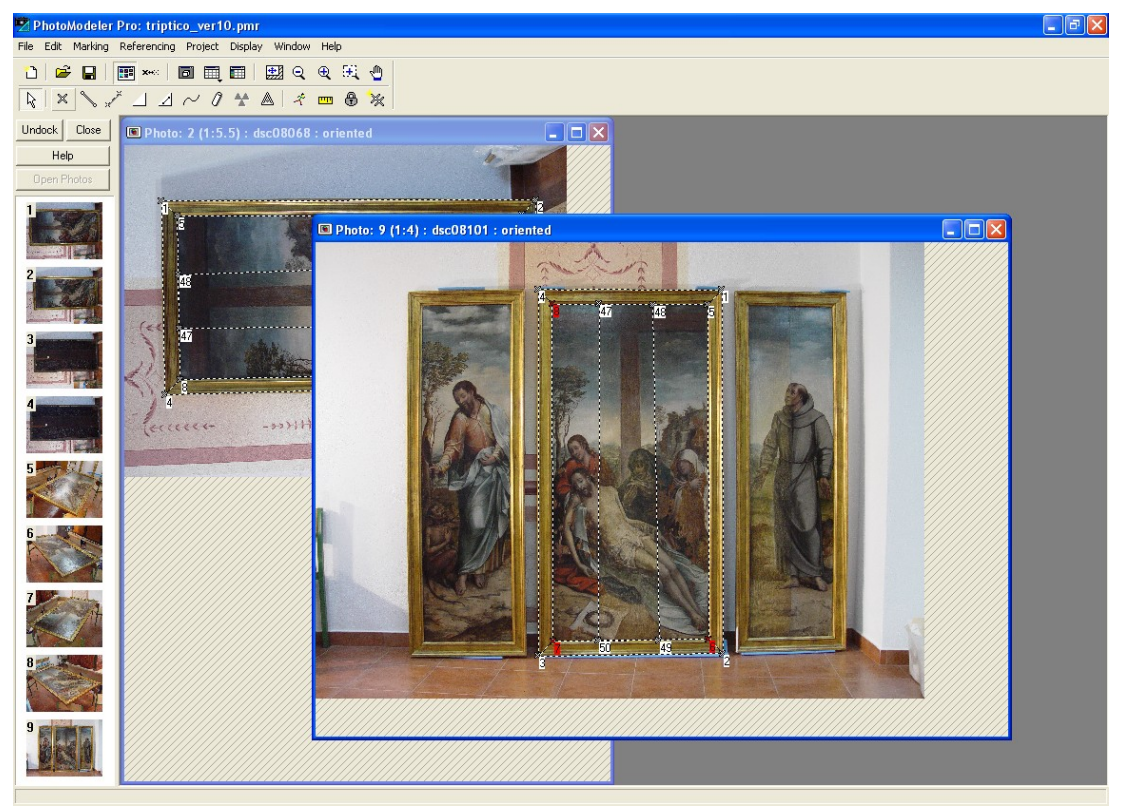

Figura 6. Marcação de pontos homólogos em ambiente fotogramétrico (Photomodeler ${ }^{\circledR}$ ).

Os procedimentos efectuados no exercício indicaram uma área de reintegração de 37,3 \% no painel central [Figura 7] e de 48,7\% no painel de "São Francisco" [Figura 8].


Figura 7. Imagem rectificada e polígono correspondente à área de intervenção na reintegração cromática de Abel de Moura no painel central da "Pietá".

Figura 8. Imagem rectificada e polígono correspondente à área de intervenção na reintegração cromática de Abel de Moura no painel de "São Francisco". 


\section{Conclusão}

Os pintores-restauradores, integrados no seu contexto temporal e sociocultural numa conjuntura política e religiosa, aplicavam as técnicas de pintura que dispunham no momento para preservar a imagem. À semelhança do que dizia Luís de Ortigão Burnay em 1945, concordamos que muitas foram as obras danificadas nas limpezas e alteradas pelos repintes, quer por falta de aperfeiçoamentos científicos, quer por desconhecimento teórico e até material dos produtos utilizados sobre as superfícies cromáticas. Mas, independentemente das razões que contribuíram para a prática dos repintes, consideramos, à semelhança do pintor-restaurador do início do século $\mathrm{XX}$, Luciano Freire, que os repintes que se pensam actualmente danosos, podem ter salvo muitas pinturas de serem colocadas à parte, e consequentemente, de desaparecerem.

Com o tempo foram-se estabelecendo linhas de fronteira entre as práticas literalmente oficinais e as de carácter mais científico. Com o desenvolvimento natural da sensibilidade humana ao Património, os responsáveis pelas acções de restauro começaram a adquirir consciência dos limites de intervenção, optando, na medida do possível, por acções mais ponderadas e criteriosas. As acções efectuadas por Abel de Moura e Fernando Mardel no campo da reintegração cromática são um manifesto da mudança de mentalidade. Ambos, quer no tríptico da "Pietá com dois Santos" quer no da "Encarnação", tentaram respeitar os limites da lacuna, assim como deixá-la bem discernível. Eram situações em que havia ablação de suporte. Terá sido a necessidade em obter continuidade na composição pictórica que conduziu às reconstituições das partes mutiladas. Embora se possam sugerir outras soluções, do ponto de vista deontológico, pensamos que as opções tomadas não foram incorrectas. Todavia, trata-se de uma questão complexa uma vez que este progresso teórico e científico está em constante desenvolvimento. Será inevitável que a materialização do processo de maturidade da reintegração cromática no século XXI incorra no futuro em novas controvérsias no que concerne à selecção da técnica de reintegração, da escolha dos materiais e, até mesmo, após a reintegração, do resultado final da imagem.

Através da informação associada às áreas produzidas pelo método descrito podemos dimensionar o espaço pictórico e a área de intervenção de Abel de Moura no painel central do tríptico da "Pietá com dois Santos" em 37,3\%, e no volante de "São Francisco" em 48,7\%. É portanto provável que, entre outros factores anteriormente anotados, sobretudo os de natureza iconográfica, a significativa dimensão da área de lacuna, que perturbava a interpretação da imagem, tivesse tido um papel fundamental na definição dos objectivos de Abel de Moura.

\section{Agradecimentos}

Agradece-se à Fundação Ricardo do Espírito Santo Silva (FRESS) a permissão da utilização das imagens do tríptico da "Pietá com dois Santos" e ao Serviço Educativo do Museu de Arte Sacra do Funchal os registos do tríptico da Igreja da Encarnação.

Artigo elaborado com o apoio do Programa Operacional Ciência e Inovação 2010 (POCI 2010), co-financiado pelo Governo Português e pela União Europeia, através do Fundo Europeu para o Desenvolvimento Regional (FEDER), da Fundação para a Ciência e Tecnologia (FCT) e da bolsa de estudos de um dos autores (SFRH / BD / 42488 / 2007).

\section{Notas}

[1] Luciano Freire nasce em 1864 e frequenta o curso de desenho e pintura na Academia de Belas Artes de Lisboa até 1886, vindo a ser professor de cátedra dessa Escola e também Académico de Mérito (Macedo, 1954: 15, 16). Segundo Afonso Vieira a actividade de Luciano Freire tem uma duração de "trinta e cinco anos". Como este dado terá sido proferido em Dezembro de 1922, o pintor 
restaurador terá iniciado a sua carreira de "reintegrador" por volta de 1887 com 23 anos. Foi em 1910 encarregue da oficina de restauro do Convento de São Francisco (Vieira, 1923: 25,27) onde coloca em prática novas metodologias, estabelecendo uma fronteira entre as práticas oficinais e as de carácter mais científico. Teve como discípulo Fernando Mardel que na continuidade de Luciano investe em procedimentos mais criteriosos, na companhia de João Couto e Abel de Moura, a partir da década de 40 .

[2] Desconhece-se, por enquanto, o motivo pelo qual Luciano Freire começa a utilizar "reintegrar" ou "reintegração" em vez de "retoque".

[3] O termo utilizado depende da localização geográfica. Por este motivo, deverá ser interpretado consoante a evolução histórica do restauro de cada país. Em Inglaterra, na Alemanha e na Áustria o termo mais comum, e usado desde sempre, é retoque: "retouching" e "retusche" respectivamente. $\mathrm{Na}$ América do Norte e Canadá utilizam “inpainting”; em França, Espanha, Itália e Portugal usam-se as palavras reintegração, integração ou retoque.

[4] Sob a tutela do Ministério da Educação e o apoio do Instituto José de Figueiredo é criada a Escola Superior de Conservação e Restauro (Decreto-lei 431/89), integrada actualmente na Universidade Nova de Lisboa. Esta escola é precedida na sua homologação pela Escola Superior de Tecnologia do Instituto Politécnico de Tomar, criada pelo Decreto-Lei n. ${ }^{\circ}$ 513-T/79 e aprovada pela Portaria n. ${ }^{\circ}$ 861, de 29 de Agosto de 1983, na II Série do Diário da Republica. Ambas deram início ao ensino universitário em 1989.

[5] Esta nossa proposta adequa-se apenas ao caso português. Para mais informações consultar SERRÃO, V. (2006). "«Renovar», «repintar», «retocar»; estratégias do pintor-restaurador em Portugal, do século XVI ao século XIX. Razões ideológicas do iconoclasma destruidor e da iconofilia conservadora, ou o conceito de «restauro utilitarista» versus «restauro científico»". Revista Conservar Património. Lisboa: Associação Profissional de Conservadores-Restauradores de Portugal. 34: 53-71.

[6] É provável que muitos dos repintes efectuados nas pinturas "primitivas" portuguesas derivem, não só das limpezas, do gosto pessoal e da época, mas também da conjuntura reformista do século XVI, com o Concilio de Trento (1545-1563), que condicionou as imagens sacras, estabelecendo limites nas representações iconográficas. Este factor levou a muitos acertos e correcções em diversas pinturas, a pedido de particulares e, sobretudo, de instituições eclesiásticas. Temos um exemplo, anotado por João Couto, que passamos a citar "E então se viu a diferença entre as duas concepções - a do pintor de quinhentos e a do pintor de seiscentos. Na interpretação do primeiro a Virgem está prostrada (...) nos braços de São João. O segundo representou a Virgem e o Apóstolo de pé, em obediência, creio eu, à doutrina do Concílio de Trento que queria a Mãe de Deus de pé, resignada e calma. (...) modificação que nos parece ter sido ditada por novo modo de ver doutrinário e não pela fantasia do pintor que renovou a composição" (Couto, 1952: 20).

[7] Por iniciativa de João Couto e do emérito físico Manuel Valadares, foi instalado em 1936 um pequeno laboratório no Museu Nacional de Arte Antiga, com um aparelho de produção de raios X. Este laboratório terá um papel primordial nestas acções de carácter científico, desenvolvidas em conjunto com a Oficina de Restauro do mesmo Museu. Além dos métodos radiográficos também se recorria à fotografia para o estudo e diagnóstico das obras. São do ano de 1923 as primeiras análises químicas, feitas por Luís Quintela e por Herculano de Carvalho, do Instituto Superior Técnico, que foram fruto de uma solicitação de Carlos Bonvalot para o restauro nos painéis da igreja matriz de Cascais. Ressalva-se ainda a iniciativa de Luísa Maria Alves e Abel de Moura em montar um laboratório científico, especificamente para apoio aos restauros, no Instituto José de Figueiredo no ano de 1969 (Alves, 2005: 3-21; Couto, 1955: 17).

[8] Este livro faz o enquadramento geral do restauro dos painéis de São Vicente, desde a descoberta até à concretização do tratamento por Luciano Freire. São anotadas as actas decorrentes das várias reuniões realizadas antes da intervenção por um grupo de eruditos portugueses. A referência bibliográfica é GONÇALVES, A. M. (1960). Do restauro dos painéis de São Vicente de Fora. Lisboa: 
[s.n.]. Para mais informações consultar ainda FIGUEIREDO, J. de. (1910). O pintor Nuno Gonçalves. Lisboa: J. Figueiredo.

[9] António José Arroio (1856-1934) foi engenheiro, autor de obras sobre literatura, música, artes plásticas e sobretudo estudioso devotado ao ensino técnico e à arte aplicada.

[10] Ramalho Ortigão (1836-1915) nasceu no Porto e estudou Direito na Universidade de Coimbra. De regresso ao Porto, dedicou-se ao ensino no Colégio da Lapa. Estabeleceu-se em Lisboa ao ser nomeado oficial da secretaria da Academia de Ciências, começando a colaborar em vários jornais e revistas. Fez várias viagens ao estrangeiro que influenciaram o seu modo de ver Portugal.

[11] O tratamento inovador de Luciano Freire não foi bem visto por todos. Segundo Afonso Vieira “ (...) alguém espalhou então em Lisboa (...) Freire vestiu de dominó o Nuno Gonçalves!” (Viera, 1923: 28). O pintor-restaurador explicou que "O preenchimento das faltas de tinta, que eram bastantes, embora nenhuma em sitio de importância de maior e (...) de diminuta área, (...) foram feitos tendo apenas em vista restituir aos painéis o aspecto harmónico inicial, sem procurar disfarces condenáveis em documentos daquela naturesa. Por que talvez hoje ainda facilmente se distingue os sítios onde se operou, não faltará quem, julgando ver aí repintadelas, não compreenda a minha intenção e o quanto ela possa ter de aceitável" (Gonçalves, 1960: 46).

[12] Luís de Ortigão Burnay, em 1945, sustenta a sua comunicação em três fontes bibliográficas: RUHEMANN, H. (1931). "16 Compromise Solutions", Mouseion, 15: 19-21; RUHEMANN, H.(1934). Technical Studies, Vol.3, n. ${ }^{\circ} 1$ e um texto de Jacques Maroger publicado em Mouseion, Vol. 19, n. ${ }^{\circ}$, p. 45. A circulação destas publicações em Portugal terá contribuído para o aumento da atitude crítica da sociedade portuguesa erudita perante o Património, e neste caso, sobre a reintegração cromática.

[13] Todo o ciclo pictórico da igreja de Santa Maria della Veritá ficou muito danificado devido aos bombardeamentos de 1940. É aqui que Cesare Brandi inaugura o novo método de restauro e reintegração de lacunas. GONZÁLES-VARAS, I. (1999). Conservación de bienes culturales. Teoría, bistoria, principios y normas. 5. ed. Madrid: Manuales Arte Cátedra, p. 262.

[14] O esgrafitado é uma técnica em que a pintura é raspada com um estilete até aparecer a camada subjacente.

[15] Trata-se de um relatório manuscrito, sem data de redacção e páginas. MARDEL, F. [s.d.]. Nossa Senhora da Encarnação. Processo de Restauro N. ${ }^{\circ}$ 977, Depósito do Instituto dos Museus e da Conservação.

[16] A ausência de imagens adequadas para o processo de ortorrectificação do tríptico da "Encarnação" levou-nos a utilizar apenas o da "Pietá com dois Santos" como exercício computacional.

\section{Bibliografia}

ALVES, L. M. (2005). "Do empirismo à ciência. Um olhar sobre o percurso da conservação em Portugal do século XIX à actualidade". Cadernos Conservação e Restauro. Lisboa: IPCR, 3: 3-21.

ARJONILLA ÁLVAREZ, M. (2008). "El conocimiento y la conservación de los Bienes Culturales a través de estratégias interdisciplinares". En Innovaciones en las Tecnologias de la Información aplicadas a la Conservación de Património, Durán Domínguez, G.; Sanjosé Blasco, J. J., (ed.). Mérida: Asociación de Gestores Culturales de Extremadura, 87-95.

BAILÃO, A. M. dos S. (2010). Metodologia e técnicas de reintegração cromática em pintura de cavalete. Porto: Universidade Católica Portuguesa. Dissertação de mestrado em Conservação de Pintura. 
BURNAY, L. de O. (1945). "Algumas considerações sobre o restauro das pinturas antigas", Boletim da Academia Nacional de Belas-Arte, Lisboa: A.N.B.A, 14: 61-70.

CASACA, J.; MATOS, J.; BAIO, M. (2000). Topografia Geral. Lisboa: Lidel.

CLODE, Luiza; PEREIRA, Fernando António Baptista. (1997). Museu de arte Sacra do Funchal. A Arte Fflamenga. Lisboa: Edicarte.

COUTO, J. (1952). Aspectos actuais do problema do tratamento das pinturas. Lisboa: Edições Excelsior,

COUTO, J. (1955). Os painéis flamengos da Ilha da Madeira. Funchal: Edição da Junta Geral do Distrito Autónomo do Funchal.

EMILE-MÂLE, G. (1976). Restauration dês peintures de chevale. Friburgo: Office du Livre.

EPPICH, R.; CHABBI, A. Recording, Documentation, and Information Management for the Conservation of Heritage Places - Illustrated Examples, (http://www.getty.edu/conservation/publications/pdf_publications/illustrated _examples1.pdf) [consulta: 8/6/2009].

GONÇALVES, A. M. (1960). Do restauro dos painéis de São Vicente de Fora. Lisboa: [s.n.].

GONZÁLES-VARAS, I. (1999). Conservación de bienes culturales. Teoría, historia, principios y normas. 5. ${ }^{a}$ ed. Madrid: Manuales Arte Cátedra.

HENRIQUES, F.; GONÇALVES, A.; BAILÃO, A.; CALVO, A. (2009). "A lacuna pictórica: metodologias de interpretação e análise", Pedra e Cal, 42: 13-15.

LEGORBURU ESCUDERO, P. (1995). Criterios sobre la reintegracion de lagunas en obras de Arte y trascendencia del estuco en el resultado final, segun su composicion y aplicacion. País Basco: Universidad País vasco, Facultad Bellas Artes. Tese de doutoramento.

LETELLIER, R. Recording, Documentation, and Information Management for the Conservation of Heritage Places Guiding principles, (http://www.getty.edu/conservation/publications/pdf_publications/guiding _principles.pdf) [consulta: 8/6/2009].

MACDONALD, L. (2006). Digital Heritage: Applying Digital Imaging to Cultural Heritage. Oxford, Burlington: Butterworth-Heinemann.

MACEDO, M. de. (1885). Restauração de Quadros e Gravuras. Lisboa: David Corazzi.

MACEDO, D. de (1954). Veloso Salgado, Luciano Freire. Lisboa: Museu Nacional de Arte Contemporânea.

MARDEL, F. [s.d.]. Nossa Senhora da Encarnação. Processo de Restauro N. ${ }^{\circ}$ 977, Depósito do Instituto dos Museus e da Conservação. Consultado em 29 de Janeiro de 2010 [fonte manuscrita].

MORA, P.; MORA, L.; PHILIPPOT, P. (1984). "Problems of Presentation". Conservation of wall paintings. Londres/Boston : Butterworths, 309- 310.

MOURA, A. de. (1949). "Les problèmes de la restauration et conservation de la Peinture". En XVI Congrés International D'Histoire de L'Art. Lisboa : Porto: Tipografia Minerva.

PHILIPPOT, A.; PHILIPPOT, P. (1959). "Le problème de l'intégration des lacunes dans la restauration des peintures”. Bulletin de l'Institut Royal du Patrimoine Artistique. Bruxelas: IRPA. Vol. 2: 5-18;

SANTOS, L. R. (1939). Os processos científicos no estudo e na conservação da pintura antiga. Porto: Imprensa social. 
TEIXEIRA, L. (1985). Dicionário Ilustrado de Belas artes. Lisboa: Presença.

VIEIRA, A. L. (1923). Da Reintegração dos Primitivos Portugueses. Lisboa: Amigos do Museu Nacional de Arte Antiga.

WALDHÄUSL, P.; OGLEBY, C. (1994). "3-by-3 Rules for simple photogrammetric documentation of Architecture". In Close range techniques and machine vision. Proceedings of the Symposium of Commission V of ISPRS, Fryer, J. G. (ed.). Melbourne, Australia: IAPRS. XXX/5: 426-429.

ZAGALLO, M. C. (1955). Catálogo da exposição de Pinturas dos Séculos XV e XVI da Ilha da Madeira (Depois do seu restauro). Lisboa: Editora Gráfica Portuguesa.

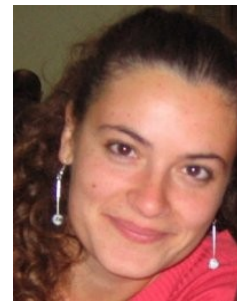

\section{A. Bailão}

Universidade Católica Portuguesa (UCP)

ana.bailao@gmail.com

Ana Bailão. Conservadora-restauradora em Pintura de cavalete. Doutoranda na Universidade Católica Portuguesa (UCP). Obtenção do grau de Mestre com o tema "Metodologia e técnicas da reintegração cromática em pintura de cavalete" pela mesma instituição. Licenciatura pré-Bolonha, pelo Instituto Politécnico de Tomar (IPT).

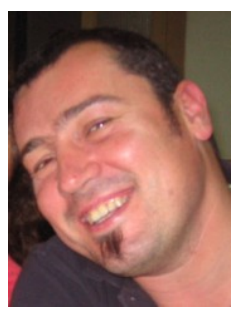

\section{F. Henriques}

Universidade Católica Portuguesa (UCP)

frederico.painting.conservator@gmail.com

Frederico Henriques. Conservador-restaurador, doutorando em Conservação de Pintura na Universidade Católica Portuguesa (UCP) em colaboração com o Dep. Eng. Civil e Arquitectura do Instituto Superior Técnico (IST). Investigador do Centro de Investigação de Ciências e Tecnologias das Artes (CITAR).

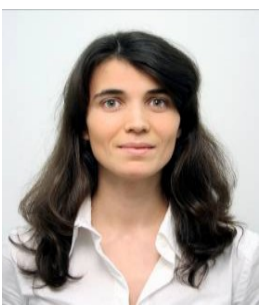

\section{Cabral}

madalenacc@gmail.com

Madalena Cabral. Licenciatura em História de Arte, Universidade de Lisboa. Concluiu recentemente o Curso de Especialização Tecnológica em Conservação e Restauro de Pintura sobre Madeira (IAO). Realizou no estágio curricular um estudo intitulado $O$ contributo das Intervenções de Abel de Moura

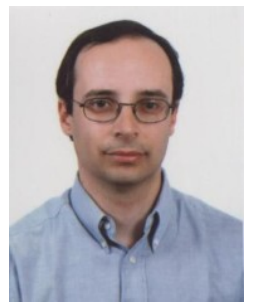

\section{A. Gonçalves}

Instituto Superior Técnico (IST)

alexg@civil.ist.utl.pt

Alexandre Gonçalves. Professor Auxiliar do Departamento de Engenharia Civil e Arquitectura do Instituto Superior Técnico (IST). Doutorado em Engenharia do Território pelo IST 